\title{
Importance of waste composition for Life Cycle Assessment of waste management solutions
}

\author{
Bisinella, Valentina; Götze, Ramona; Conradsen, Knut; Damgaard, Anders; Christensen, Thomas \\ Højlund; Astrup, Thomas Fruergaard
}

\section{Published in:}

Journal of Cleaner Production

Link to article, DOI:

10.1016/j.jclepro.2017.07.013

Publication date:

2017

Document Version

Peer reviewed version

Link back to DTU Orbit

\section{Citation (APA):}

Bisinella, V., Götze, R., Conradsen, K., Damgaard, A., Christensen, T. H., \& Astrup, T. F. (2017). Importance of waste composition for Life Cycle Assessment of waste management solutions. Journal of Cleaner Production, 164, 1180-1191. https://doi.org/10.1016/j.jclepro.2017.07.013

\section{General rights}

Copyright and moral rights for the publications made accessible in the public portal are retained by the authors and/or other copyright owners and it is a condition of accessing publications that users recognise and abide by the legal requirements associated with these rights.

- Users may download and print one copy of any publication from the public portal for the purpose of private study or research.

- You may not further distribute the material or use it for any profit-making activity or commercial gain

- You may freely distribute the URL identifying the publication in the public portal 


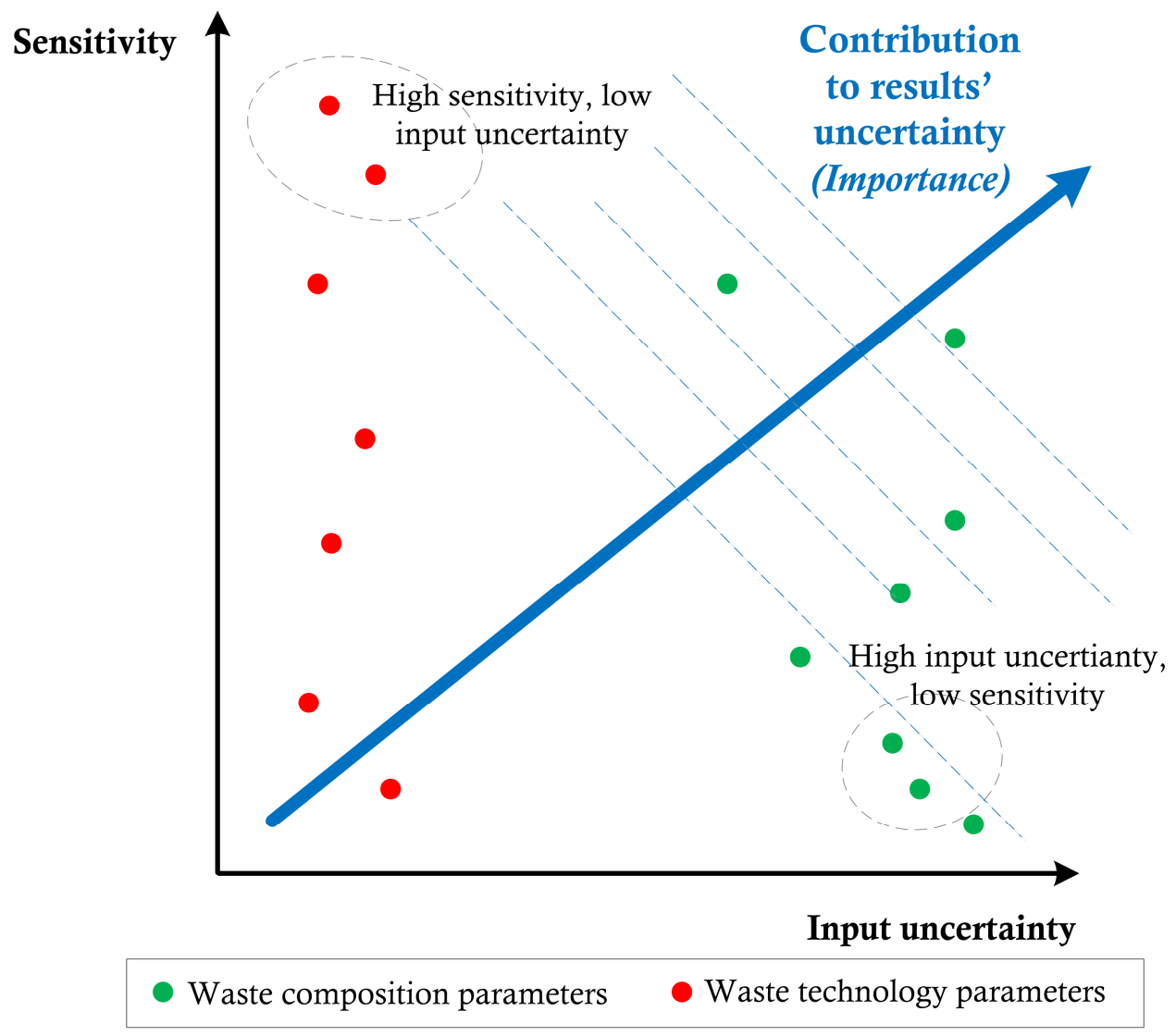




\title{
IMPORTANCE OF WASTE COMPOSITION FOR LIFE CYCLE ASSESSMENT OF WASTE MANAGEMENT SOLUTIONS
}

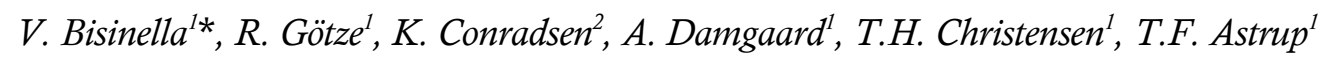

1) Technical University of Denmark, Department of Environmental Engineering, Bygningstorvet, Building 115, 2800 Kongens Lyngby, Denmark

2) Technical University of Denmark, Department of Applied Mathematics and Computer Science, Richard Petersens Plads, Building 321, 2800 Kongens Lyngby, Denmark

*Corresponding author. Tel: +45 4525 51443, E-mail: valenb@env.dtu.dk

\begin{abstract}
The composition of waste materials has fundamental influence on environmental emissions associated with waste treatment, recycling and disposal, and may play an important role also for the Life Cycle Assessment (LCA) of waste management solutions. However, very few assessments include effects of the waste composition and waste LCAs often rely on poorly justified data from secondary sources. This study systematically quantifies the influence and uncertainty on LCA results associated with selection of waste composition data. Three archetypal waste management scenarios were modelled with the waste LCA model EASETECH based on detailed waste composition data from the literature. The influence from waste composition data on the LCA results was quantified with a step-wise Global Sensitivity Analysis (GSA) approach involving contribution, sensitivity, uncertainty and discernibility analyses. The waste composition data contributed significantly to the LCA results and the uncertainty associated with these results. The importance of 405 individual waste properties was evaluated in comparison with 345 technology parameters. Overall, less than 10 physico-chemical properties
\end{abstract}


dominated the output uncertainty of the LCA results, although these properties had low sensitivity in the model. Moreover, the uncertainties associated with the physico-chemical properties were responsible for output uncertainties that spanned from impacts to benefits. The GSA approach applied in this study constitutes a valuable tool for systematically assessing the importance of waste composition and for consciously collecting and using waste composition data within LCAs of waste management systems.

Keywords: Life Cycle Assessment; waste composition; physico-chemical composition; fractional composition; Global Sensitivity Analysis; uncertainty analysis

$\begin{array}{ll}\text { Abbreviations } & \\ \text { TS } & \text { total solids (dry matter content) } \\ \text { VS } & \text { volatile solids } \\ \text { GSA } & \text { global sensitivity analysis } \\ \text { SC } & \text { sensitivity coefficient } \\ \text { SR } & \text { sensitivity ratio } \\ \text { NSR } & \text { normalized sensitivity ratio } \\ \text { GW } & \text { climate change } \\ \text { OD } & \text { stratospheric ozone depletion } \\ \text { HTC } & \text { human toxicity, cancer effects } \\ \text { HTNC } & \text { human toxicity, non-cancer effects } \\ \text { IR } & \text { ionizing radiation } \\ \text { POF } & \text { photochemical ozone formation } \\ \text { FE } & \text { freshwater eutrophication } \\ \text { ME } & \text { marine eutrophication } \\ \text { ET } & \text { freshwater ecosystem toxicity }\end{array}$




$\begin{array}{ll}\text { RDFOS } & \text { fossil resources depletion } \\ \text { RD } & \text { metals/minerals depletion } \\ \text { TA } & \text { terrestrial acidification } \\ \text { TE } & \text { terrestrial eutrophication } \\ \text { PM } & \text { particulate matter }\end{array}$

\section{Introduction}

The composition of waste materials is of fundamental importance not only for emissions during waste treatment (e.g. incineration) and final disposal (e.g. landfilling), but also for the potential recovery and recycling of useful resources. The chemical composition of the waste also plays a fundamental role for the sustainability of circular economy paradigms (European Commission, 2015) within the increasing complexity of material cycles (i.a. Pivnenko and Astrup, 2016). Thereby the waste composition may directly influence the environmental performance of individual waste management solutions. For Life Cycle Assessment (LCA) of waste management, this means that the type of materials present in waste (e.g. paper, plastic, metals, and organic fractions), as well as the chemical composition of these materials, may critically affect the results from LCA modelling. As such, waste composition - and the data representing this - plays an important role for environmental assessments of waste solutions, as well as for the sustainability of transforming linear production into cycles of materials. Despite this, very few examples exist in which these aspects have been discussed from an LCA perspective. So far, the importance of waste composition data in waste LCA modelling has not been quantified.

The reference flow of waste-related LCAs is typically defined as a specific amount of waste, often composed of heterogeneous materials. These materials are usually characterized at a fractional and a physico-chemical level, representing the so-called waste composition (e.g. Götze et al., 2016). The fractional composition quantifies the proportions between waste material fractions (e.g. plastic, paper, metal, etc.), while the physico-chemical composition quantifies the properties associated with each of 
these fractions (e.g. calorific value, $\mathrm{Ca}$ and $\mathrm{Cd}$ contents, fossil C, biogenic C, etc.). So far, most LCA studies in literature involving waste management have heavily relied on secondary data, typically obtained from a mix of different studies in the literature (e.g. Aye and Widjaya, 2006; Cherubini et al., 2008; Fruergaard and Astrup, 2011; Arena and Di Gregorio, 2014). As also pointed out in the literature, waste composition data may significantly influence the results (e.g. Slagstad and Brattebø, 2013; Clavreul et al., 2012; Laurent et al., 2014). Due to the unavailability of international standard methodologies for characterizing the waste (Christensen et al., 2009; Edjabou et al., 2015; Gentil et al., 2010), the various data sources involve a variety of assumptions, analytical methods, and spatiotemporal scopes that ultimately result in high uncertainty (Astrup et al., 2011; Laurent et al., 2014a), especially associated with the physico-chemical properties of the waste (Götze et al., 2016). Ideally, waste LCA studies should quantify to which extent the waste composition data affects the LCA results as well as the final uncertainty of these results. This has, however, never been done.

The multi-allocation feature of waste LCAs has been addressed by linking part of the emissions to specific properties of the reference flow (e.g. Finnveden et al., 1995). Similarly, Köhler et al. (2007) and Li et al. (2013) created a causal relationship between emissions and properties of the input flow for wastewater treatment LCA. Nielsen and Hauschild (1998) investigated effects of changes in the waste input in emissions arising from different landfill types. They indicated that estimating environmental emissions using the composition of the input waste was more appropriate than simply neglecting the influence from the waste. Variations in LCA results originating from variations of the amounts of waste material fractions were addressed by Christensen et al. (2009), Passarini et al. (2012) and Slagstad and Brattebø (2013). Here, it was highlighted that different fractional compositions did not change the ranking of the environmental performance of the scenarios assessed.

LCA results are not always influenced by waste composition data. This is only the case when the LCA model supports tracking of the individual material fractions and their associated chemical characteristics throughout the waste management scenario (Laurent et al., 2014b). An example of such a model is EASETECH (Clavreul et al., 2014). Most LCA tools (e.g. GaBi and SimaPro) do not allow 
modelling of a reference flow consisting of a mix of materials and tracking of emissions from waste to the environment (Clavreul et al., 2014). For these more generic tools, Life Cycle Inventories (LCIs) are often based on "average" or "modelled" reference flows with emissions that represent "average values" for a particular waste treatment technology, and without reference to the specific input waste in question (Turconi et al., 2011). Consequently, these models ignore any effects from the waste composition. Dedicated waste LCA models, e.g. EASETECH, allow a more accurate representation of the waste materials and distinguish between direct and indirect contributions from the reference flow to the emissions. Uncertainty propagation in waste LCAs has been addressed on a parameter level (i.e. input values in the LCA model) and organized in step-wise procedures (Bisinella et al., 2016; Clavreul et al., 2012). Like for any other scenario parameter value, the importance (contribution to the uncertainty of the results) of waste composition data can be quantified through Global Sensitivity Analysis (GSA), i.e. accounting both for the sensitivity of a parameter in a specific scenario configuration and for the intrinsic uncertainty of this parameter.

Recent reviews have revealed that the selection of waste datasets most often is poorly described and inadequately justified (Astrup et al., 2015), despite the relevance of quantifying the importance of waste composition data in waste LCAs and the availability of dedicated tools. So far, the variations in LCA results caused by the choices of the waste dataset have been addressed only qualitatively or by means of scenario analysis (Slagstad and Brattebø, 2013) and without any quantitative contribution, sensitivity, or uncertainty analyses. Previous studies on uncertainty propagation in waste LCAs have focused more on uncertainty from technical parameters and only on a small selection of waste properties (Bisinella et al., 2016; Clavreul et al., 2012). On the other hand, relatively large variations have been reported for physico-chemical waste properties (Götze et al., 2016).

The aim of this study is to provide an in-depth analysis of the importance of waste composition for LCA results of waste management solutions. This includes the following more specific objectives: i) application of GSA for quantification of uncertainties in the results associated with waste composition data; ii) quantification of the importance of waste composition data with respect to both direct and 
indirect contributions to average results and uncertainty; and iii) identification of critical physicochemical properties of the waste.

The GSA approach and assessment method are presented in Section 2. The study applies a literature dataset with quantified uncertainties for assessment of three illustrative waste management scenarios representing archetype European waste solutions. The results of the GSA approach, presented in Section 3, are discussed in Section 4 with specific focus on the i) applicability of uncertainty assessment for waste composition data, and ii) specific challenges associated with application of highly uncertain waste composition data in comparative LCAs of waste management over multiple impact categories.

\section{Materials and methods}

This study quantitatively examined the effects of waste composition data on LCA results and uncertainty. A waste composition dataset obtained from a comprehensive literature review and complete with uncertainty was utilized in an LCA model assessing three archetypal waste management solutions. The effects on results and uncertainty were quantitatively assessed with a GSA approach involving contribution, sensitivity, uncertainty and discernibility analyses. The LCA model was a dedicated waste-LCA tool. The quantitative assessment of the LCA model results was performed in Excel spreadsheets. The following Sections present the waste composition data, the LCA model, the assessment method and the waste management case study.

\subsection{Waste composition data}

For this study, a comprehensive waste composition dataset with quantified uncertainties was needed. Such a dataset was obtained through a combination of three sources:

i) Data for the relative shares of individual material fractions in Danish household waste (Edjabou et al., 2015);

ii) Data for the physico-chemical properties for numerous waste material fractions obtained from a literature review of 97 publications (Götze et al., 2016); 
iii) Data for Total Solids (TS) and the associated moisture content of material fractions in Danish household waste (Riber et al. 2009, also included in Götze et al., 2016).

In combination, the dataset represents typical Danish household waste, but assuming that the physico-chemical properties of individual material fractions actually vary according to the ranges found in literature. Therefore, the dataset can be considered to represent the maximum uncertainty ascribable to the current waste composition variability in the literature. While a concrete study may involve casespecific data with lower uncertainties, the selected dataset is considered appropriate for the purpose of this study. Table 1 presents selected parameters of the dataset. For details regarding the items used for the waste composition, please refer to the Supplementary Material (Tables S8 and S9). The combined waste dataset included three types of data: i) relative distribution of material fractions in the waste (weight percentages out of total mass); ii) dry matter content of the individual material fractions (weight percentages of fraction mass, TS); and iii) physico-chemical properties of the dry matter of the material fractions (weight percentages of TS, e.g. \% Cd).

Parameters such as volatile solids (VS) and ash contents were retrieved as \% TS from Götze et al. (2016). Since Edjabou et al. (2015) used a larger number of fractions than Götze et al. (2016), nine common material fractions were defined: food waste, gardening waste, paper and cardboard, composites, plastic, combustibles, metal, glass, and inert waste (see Table 1).

The modelling used median values of the physico-chemical data provided by the distributions in Götze et al. (2016) for the corresponding fractions of Edjabou et al. (2015). Uncertainties were assumed to be described by triangular probability distributions characterized by the minimum, maximum and mode values from Götze et al. (2016). As the mode values frequently coincided with either the minimum or the maximum, the distributions were highly skewed with large coefficients of variation (CV), especially for the metals (Table S9, Supplementary Material). Uncertainties related to the fractional composition were assumed to be triangularly distributed as well, with a $10 \%$ uncertainty around the mean value for all material fractions. 
The waste composition dataset of Riber et al. (2009) was selected as reference illustrating an individual dataset that has been applied in a wide range of waste LCA studies both for Danish conditions as well as for other regions (e.g. Jensen et al., 2016; Montejo et al., 2013; Tonini and Astrup, 2012). The material fractions of this dataset were aggregated according to the same nine material fractions mentioned above. No uncertainties existed for the data from Riber et al. (2009). As such, this dataset represented an example of a singular dataset widely applied for waste LCAs. Single-point results based on this dataset were used for comparison with results based on the "literature dataset".

\subsection{LCA model implementation}

The LCA was carried out with the EASETECH model (Clavreul et al., 2014). As previously mentioned, EASETECH allows modelling of the reference flow as a collection of material fractions with tracking of their composition throughout the modelled technologies (similar to material flow analysis, MFA). This means that emissions from the waste technologies are affected both by the distribution of material fractions in the reference flow as well as the physico-chemical properties associated with these material fractions. Consumption and production of external processes (LCIs) in the background system can be expressed per unit of reference flow (e.g. amount of treated waste), but may also be expressed per property of reference flow (e.g., energy recovered per MJ of energy in the reference flow). Emissions occurring in the foreground system (e.g., during waste treatment) can be connected to treatment technology (e.g., amount of dioxins produced during incineration of the reference flow) or directly emitted based on the reference flow (e.g. amount of mercury emitted per amount of mercury in the reference flow). Traditionally, the LCI of each waste technology process is divided in three parts: i) input-specific, ii) process-specific and iii) external LCIs (background processes). Here, the process-specific and external LCIs are further subdivided into: i) processspecific/external LCI per unit of reference flow and ii) process-specific/external LCI per property of reference flow (Figure 1). The latter subdivision allows tracking for indirect input-specific emissions related to the waste properties (e.g., TS content, physico-chemical properties). EASETECH allows the 
user to parametrize inventory data entries as i) single values, ii) a list of values, or iii) a probability distribution (normal, uniform, lognormal or triangular). The assigned uncertainties are propagated within EASETECH based on Monte Carlo simulations for calculation of the output uncertainty of the LCA results. For parameterization and further details regarding the modelling in EASETECH, please refer to the Supplementary Material for examples (Section S3).

\subsection{Assessment method}

The results were evaluated based on a step-wise approach for quantitative uncertainty assessment provided by Bisinella et al. (2016) for the full list of ILCD-recommended impact categories (European Commission, 2010). The following GSA framework was applied with focus on the three types of waste input data as well as on the relevant technology parameters (for details, please refer to Supplementary Material, Tables S4 - S6):

- Step 0. Contribution analysis: Calculation of LCA results; quantification of direct (input-specific) and indirect (LCI or process-specific emissions per property of the reference flow) contribution of waste composition to the results.

- Step 1. Sensitivity analysis: One-at-a-time (OAT) perturbation of each scenario parameter (both waste input and technology parameter: e.g., fossil C content of plastic waste, electricity recovery from incineration, etc.) by $10 \%$ and calculation of sensitivity coefficients (SCs) and sensitivity ratios (SRs). On this basis, normalized sensitivity ratios (NSRs) were calculated, see Eq. (1). For $i=1, \ldots, n$ representing the tested parameters and $j=1, \ldots, m$ representing the impact categories, then the NSRs are defined as:

$$
N S R_{i}^{j}=\frac{\left|S R_{i}^{j}\right|}{\max \left(\left|S R_{i}^{j}\right|\right)^{j}}
$$

Identification of the most sensitive parameters in the individual scenarios is then done by rankordering the calculated coefficients. 
- Step 2. Global importance analysis: Analytical quantification of uncertainty contributions from waste composition and technology parameters (Figure 1) by multiplication of parameter input uncertainty (variances) with corresponding $\mathrm{SC}^{2}$ obtained from Step 1. Identification of the most important parameters based on rank-ordering of the output uncertainties. Approximate quantification of the total scenario uncertainty and coefficient of variation (CV) by summing output uncertainties for all individual parameters.

- Step 3. Uncertainty propagation and discernibility analysis:

a) Uncertainty propagation. Distributions of LCA results (displayed as uncertainty ranges around average results) obtained from Monte Carlo simulations (1000 runs). Subsequent evaluation of these result distributions with the analytical uncertainty results from Step 2, both for single parameters and for the full parameter sets, as well as the average results obtained from Step 0.

b) Discernibility analysis. Quantification of preference of one scenario over another (as percentages representing the probability of one scenario performing better than others) based on pair-wise comparisons of results for individual Monte Carlo samples.

Fractional and TS parameters do not comply automatically with the assumption of independence that is underlying both the analytical and Monte Carlo uncertainty propagations (Bisinella et al., 2016). By varying the fractional composition also TS is affected (given as percentage of waste fraction weight). Similarly, also the physico-chemical properties of the reference flow are affected because these parameters are expressed relative to TS. In order for the functional unit to be respected during OAT perturbations and calculations of SRs, the reference flow was always "re-normalized" to the selected unit of 1 tonne. Results for fractional and TS parameters were kept separate throughout the quantified uncertainty assessment to ensure transparency.

\subsection{Waste management case-study}


For illustration of the importance of waste composition data, three waste management scenarios for treatment of Danish household waste were assessed. The scenarios were adapted from Jensen et al. (2013) and Bisinella et al. (2016). The main features of the three scenarios are: (S1) source segregation and recycling of paper, cardboard and glass and incineration of the residual waste with energy recovery; (S2) same as S1 but with additional source segregation of organic waste routed to anaerobic digestion and on-land application of digestate; (S3) same as S1 but with landfilling of the residual fraction. The technology process models were obtained from the process library of EASETECH (Clavreul et al., 2014). The following impact categories were included: climate change (GW), stratospheric ozone depletion (OD), human toxicity, cancer (HTC) and non-cancer effects (HTNC), ionizing radiation (IR), photochemical ozone formation (POF), freshwater eutrophication (FE), marine eutrophication (ME), freshwater ecosystem toxicity (ET), fossil resources depletion (RDFOS), and metals/minerals depletion (RD), terrestrial acidification (TA), terrestrial eutrophication (TE) and particulate matter (PM). Characterization methods and normalization references were selected among those recommended by the ILCD (European Commission, 2010). The time horizon is 100 years and the reference flow 1 tonne of waste. The modelling followed a consequential approach with multi-functionality addressed by substitution. Please refer to the Supplementary Material for detailed descriptions of scenarios, waste technologies and data uncertainty.

\section{Results}

\subsection{Normalized results}

Figure 2 presents the normalized impact scores in person equivalents $(\mathrm{PE})$ for the dataset from Götze et al. (2016) for S1, S2 and S3. The magnitude of impacts and savings varied significantly among scenarios and impact categories, with relatively similar results for $\mathrm{S} 1$ and $\mathrm{S} 2$ for $\mathrm{OD}, \mathrm{IR}, \mathrm{RD}, \mathrm{POF}, \mathrm{TA}$, $\mathrm{TE}$ and PM due to the shared processes of incineration and material recycling. S1 provided the lowest impacts for all impact categories except FE, mostly due to the higher share of incinerated waste and energy recovery. S2 provided the largest benefits in the FE impact category due to substitution of 
mineral fertilizer with the nutrients contained in the digestate produced from anaerobic digestion of organic waste. However, S2 also showed the highest impacts in the categories HTNC and ET due to metal emissions to soil by application of digestate on agricultural land. Overall, S3 had considerably lower benefits than S1 and S2. S3 obtained the highest impacts especially for ME due to management of landfill leachate, but also for the impact categories OD, HTC, POF, FE, ET and TE.

Normalized results for the three scenarios were also determined based on the dataset from Riber et al. (2009) (Figure 2). For S1, the Riber et al. (2009) dataset provided higher savings mostly due to the higher energy content of the waste, while higher impacts were observed due to heavy metal concentrations that were higher than the averages reported in Götze et al. (2016). The results for the two datasets provided the smallest difference for S3, which was characterized mainly by processspecific impacts, except for GW where Riber et al. (2009) provided higher impacts due to higher contents of anaerobically degradable C. While the ranking between scenarios within the individual impact categories was not affected by the two datasets, the results differed in absolute magnitude. This illustrates that the waste composition cannot be ignored a priori.

\subsection{Contribution analysis}

The relationships between waste composition data and the results were different for the three scenarios, due to the different technologies included in the scenarios. Figure 2 presents the contribution analysis results. See Table 2 for an overview of absolute contributions from the waste composition data (input-specific emissions) to the results for each scenario and impact category.

For S1, the influence from waste composition data was dominated by incineration. LCIs for electricity and heat recovery are linked to the energy content of the waste input, while direct inputspecific emissions occur for fossil $\mathrm{C}$ and metals (As, $\mathrm{Cd}, \mathrm{Cr}, \mathrm{Cu}, \mathrm{Ni}, \mathrm{Hg}, \mathrm{Pb}$ and $\mathrm{Sb}$ ). For $\mathrm{GW}, 30 \%$ of the impacts were associated with direct input-specific emissions, while LCIs associated with background processes contributed with up to $50 \%$ in most of the impact categories. 
In S2, the results were affected also by the waste composition data through the anaerobic digestion process. The anaerobically degradable part of $\mathrm{C}$ influences the amount of produced biogas, which is linked both to emissions to air and digestate production. Direct biogas emissions to air are thus input-specific, while background processes associated with electricity and heat substitution from biogas combustion are connected to the properties of the input, like other process-specific emissions. Moreover, $\mathrm{N}$ and biogenic $\mathrm{C}$ in the waste affect direct input-specific emissions from the digestate to air during stabilization and to soil and water during use-on-land. Biogenic $\mathrm{C}$ also affects soil carbon contents (and storage), leading to input-specific savings. Application of digestate on agricultural land causes input-specific emission of metals ( $\mathrm{As}, \mathrm{Cd}, \mathrm{Cr}, \mathrm{Cu}, \mathrm{Ni}, \mathrm{Hg}, \mathrm{Pb}, \mathrm{Sb}$ and $\mathrm{Zn}$ ) as well. The substitution of mineral fertilizer production is linked to the input contents of nutrients in the waste $(\mathrm{N}$, $\mathrm{P}, \mathrm{K})$, to which also the avoided process-specific emissions of heavy metals from saved fertilizers are connected. Direct waste input-specific emissions were significant for several categories: GW (28\%) and ME (24 \%), but especially for HTC (68 \%), HTNC (91\%), and ET (77\%) due to metals emissions to soil. The LCIs of background processes linked to the input mostly affected FE results (90\%) through fertilizer substitution.

For S3, the results were influenced by the waste composition data only through biogenic and anaerobically degradable $\mathrm{C}$. The anaerobically degradable part of the $\mathrm{C}$ affects biogas and leachate generation, and thus the emissions associated with these flows. Other gaseous emissions within the landfill gas were modelled as process-specific emissions per property of the input, similar to processspecific emissions associated with landfill gas combustion and oxidation through the top cover. The LCIs associated with electricity and heat substitution from gas utilization were connected to the input through the amount of biogas produced. Regarding leachate, concentrations of substances were obtained as process-specific emissions; thereby emissions through leachate were indirectly connected to the anaerobically degradable $\mathrm{C}$. Finally, the biogenic $\mathrm{C}$ is linked directly to the saved emissions from stored C. Direct input-specific impacts primarily affected GW (32\%) due to C storage in soil. In this 
scenario, the process-specific emissions were dominating the results for OD (99\%), HTC (97 \%), FE (80\%), ME (96\%) and ET (75\%).

\subsection{Sensitivity analysis}

Ranking of SRs and NSRs for each scenario and impact category can be found in the Supplementary Material (Tables S11 - S16). Overall, the relative shares of the material fractions mostly provided higher SRs than the TS or the physico-chemical properties. In rankings involving only physico-chemical and technology parameters, the technology parameters generally provided the highest sensitivities. Parameters such as electricity and heat recovery and source segregation efficiencies were among the most sensitive parameters, in accordance with Bisinella et al. (2016), while nutrients and metal concentrations generally provided relatively low sensitivities. It should be realised, however, that energy recovery is indirectly affected by the input energy content (and thereby also by the waste composition data). The highest variations from the median results were provided by the following technology parameters: process-specific NOx emissions from the incinerator for $\mathrm{S} 1$, heat recovery for S2 and water infiltration in the landfill for S3.

\subsection{Global importance analysis}

The previously calculated SCs were utilized to determine the output uncertainty analytically based on the input uncertainty. Rankings of the resulting uncertainties for each scenario and impact category are provided in the Supplementary Material (Tables S17 - S22), reporting the percentage of the scenario output uncertainty associated with each parameter, as well as the average CV from the median result in the individual impact categories. Figure 3 summarizes the percentage of output uncertainty associated with the physico-chemical (input-specific) and technology parameters. The technology parameters were subdivided into "technology" and "technology per property of input", depending on whether the parameters were related to background processes (external LCIs) or to process-specific emissions per mass or per property of the reference flow, respectively (Figure 1). 
The output uncertainty was mainly characterized by the physico-chemical properties, especially for S1 and S2. On average, the absolute contribution to the uncertainty from the physico-chemical properties was $81 \%$ for S1, $92 \%$ for S2 and $77 \%$ for S3. Parameters connected to the fossil C, VS and energy content dominated the output uncertainty for most impact categories, as also illustrated by the contribution and sensitivity analysis. Electricity and heat recovery efficiencies had considerably less importance. The input metal concentrations, which had low SRs, were the parameters primarily responsible for the uncertainty for HTC, HTNC and ET. For S3 most of the uncertainty was associated with biogenic $\mathrm{C}$ and associated technical parameters (e.g. additional substances emitted per volume of biogas produced, gaseous emissions from the landfill top cover). Overall, parameters that did not score any SC also did not contribute to the output uncertainty. The largest CVs were obtained for HTC and RD in S1, HTC, HTNC, ET and TE in S2, and OD in S3. This was due mainly to the large output uncertainty associated with metal contents in the waste. An approximate analytical output uncertainty was also calculated for the fractional and TS parameters, with the results reported in Tables S17 - S19 (Supplementary Material). These results indicate that the fractional parameters may be important for the output uncertainty, despite the limited input uncertainty of these parameters.

Following the procedure of Bisinella et al. (2016), the individual parameters were rank-ordered according to their contribution to the output variance. Using this ordering, the accumulated sums of the variances were obtained, and the number and the nature of the parameters contributing mostly to the overall scenario uncertainty were assessed, see Figure S4 in Supplementary Material. For all scenarios, the model output uncertainty could be sparsely represented by only a limited number of parameters. For S1, only 18 out of 417 model parameters were required to represent $90 \%$ of the model output uncertainty across all 14 impact categories. Of these 18, only five were technology parameters, while the remaining 13 were waste input properties: mostly $\mathrm{C}$ fossil, energy, $\mathrm{VS}$ and metal $(\mathrm{Cu}, \mathrm{Hg}, \mathrm{Pb})$ contents in individual waste material fractions. For S2, more than the $90 \%$ of the model output uncertainty was represented by 23 out of 463 model parameters, across all impact categories. Only three of the 23 parameters were technology-related, while the majority of the model output uncertainty 
originated from physico-chemical waste properties: metals $(\mathrm{Cu}, \mathrm{Hg}, \mathrm{Pb}, \mathrm{Zn})$ nutrients $(\mathrm{N}, \mathrm{P})$ and anaerobically degradable carbon content of different waste material fractions. For S3, uncertainty propagation for only 18 out of 624 model parameters was needed to represent more than the $90 \%$ of the model output uncertainty. Only three of these 18 parameters were directly linked to the biogenic and anaerobically degradable $\mathrm{C}$ of the waste. However, the majority of the remaining technical parameters was indirectly linked to the same input-specific properties through the volume of biogas produced. Please refer to Tables S20 - S22 for a detailed summary of the contributions for each scenario and impact category.

\subsection{Uncertainty propagation and discernibility analysis}

The total analytical uncertainty showed an average deviation of $5 \%$ from the Monte Carlo results, complying with the observations of Bisinella et al. (2016). In particular, the fractional and TS parameters showed very large variations between the two uncertainty assessment methods. For this reason, the importance of these two types of parameters is addressed in the following discussion. The LCA results are provided as distributions in Figure 4, without the contributions from fractional and TS parameters. Results are thus provided for a fixed fractional composition and fixed TS. The columns represent the averages from the Monte Carlo sampling and the error bars represent the $5^{\text {th }}$ and the $95^{\text {th }}$ percentiles of the results distributions. For comparison, individual data points illustrating single-point results are provided from median values of Götze et al. (2016) and the Riber et al. (2009) datasets.

The output uncertainties are proportional to the magnitude of the results, but generally present large CVs, with average values of $100 \%$. The distributions are most often non-symmetrical due to the skewed input uncertainties. As a result, for some impact categories the deviations between the results of median values from Götze et al. (2016) and the averages of the Monte Carlo samples were considerable. The impact categories characterized by the highest deviation were: HTC (-119\%), HTNC (9663 \%), ET (81 \%) and RD (-147\%) for S1, HTC (1824\%), HTNC (1317\%) and ET (1863 \%) for S2 and OD (-97 \%) for S3. For S1 and S2, the output uncertainty of HTC, HTC, ET and RD is governed 
by the physico-chemical properties: $\mathrm{Cu}, \mathrm{Hg}, \mathrm{Zn}$ and VS. For OD in S3, the uncertainty is characterized by technical parameters. The corresponding $\mathrm{CV}$ is also significantly different from the analytically calculated CVs. However, the impact categories for which this occurs do also have high analytical CVs. This suggests that the analytical CVs could be used to indicate cases where the uncertainty associated with the average results is potentially affected by extremely skewed input uncertainties. Thus the analytical CVs may indicate when Monte Carlo simulations are needed to calculate uncertainties of the results. Using this approach may limit the need for Monte Carlo simulations and thereby lighten the computational requirements.

We now wish to compare the performance of the three scenarios taking the output uncertainty range into account. The results overlapped for most impact categories with exception of OD, IR, FE, TA and PM (however, always S3 showing inferior performance). Moreover, the uncertainty range for HTNC, ME, RD in S1, for POF, ME and RD in S2 and GW in S3 included both negative and positive values, indicating that the results can potentially change between benefits and burdens according to the contribution from physico-chemical properties. This is very important and illustrates the necessity of including uncertainties. The discernibility analysis in Table 3 shows that S1 still represents the best solution for all impact categories, with exception of FE. However, the input uncertainty diminishes the potential advantage of S1 especially for OD, HTNC and IR. In Table 3, percentages close to $50 \%$ indicate the largest possible overlap between the results. The uncertainty contribution analysis obtained from the GSA identifies the parameters contributing the most to the overlap of results. In the cases where S1 and S2 overlap, the uncertainty is most often associated with the same physico-chemical properties related to the shared incineration process ( $G W, O D, I R, P O F, R D, T A, T E$ and $P M)$. In the case of FE, the parameter contributing to the highest savings of S2 is P in food waste. The highest overlap occurs for HTNC, with the highest contributions from input-specific metals emissions for S1, and input-specific anaerobically degradable $\mathrm{C}$ and process-specific metal leaching for S3.

\section{Discussion}




\subsection{Direct and indirect influence on results}

Only a selected number of physico-chemical properties analyzed by Götze et al. (2016) affected the results, directly and indirectly. While the modelling of waste technologies complies with state-ofthe-art waste LCA studies (Clavreul et al., 2014), the inherent choices of LCIs representing substituted processes (glass and paper recycling, energy and heat technologies, mineral fertilizers, etc.) could potentially change the magnitude of savings and change the effect of the properties of the input waste flow on the results. This conclusion is often brought forward by waste LCA studies, e.g. (Fruergaard and Astrup, 2011; Turconi et al., 2011). However, based on the contribution analysis it was shown that the waste composition not only affects the direct input-specific contributions but also indirectly affects the contributions from process-specific emissions and emissions from external process LCIs. This is due to the linkage to properties of the waste (e.g. energy content with energy recovery and methane emissions with degradable C). So far, no waste LCA studies have quantified the importance of these contributions.

The data quality of external LCIs can also affect the contribution to results linked to the waste input. This may be due to lacking emission data and thus not contributing to impacts in some impact categories, or due to lowering the quality and representativeness of the waste composition data when linked to low-accuracy LCIs. Changes in the energy framework for substitution of electricity and heat, e.g. towards cleaner and fossil-free energy technologies, considerably change the impacts and savings connected to the waste input: this affects the indirect input-specific contributions to the results, but not the direct input-specific emissions or savings (e.g. C storage). This mechanism exists irrespective of the considered LCA scope. Thereby, the contribution analysis is suitable also for isolating parts of the results that could be affected by potential changes in the background system and, most importantly, which others would not change.

For all modelled scenarios the absolute direct and indirect contribution of the waste composition was $48 \%$ in average. This clearly indicates that a large share of the environmental impacts associated with waste management is related to the waste input composition. Without LCA models that include 
both direct and indirect effects from waste composition, or at least without LCIs appropriate for the specific waste flows in question, the results from LCA studies of waste management are unlikely to represent reality.

\subsection{Benefits of the GSA approach and uncertainty propagation}

The results of the GSA and Monte Carlo uncertainty propagation showed high potential variability associated with the waste composition data available in literature. The contributions to the output uncertainty varied among the scenarios and impact categories, but had lower contributions for S3. The largest absolute uncertainties were related to impact categories connected with metal emissions.

The full importance of waste composition data can be quantified through the GSA approach by combining parameter sensitivity (SC which depends on the model structure) with input data uncertainty (actual variability of the parameters). The analytical uncertainty approximates the sampled uncertainty of the waste data adequately, but with considerably lower computational efforts. The results showed that the waste related physico-chemical properties were in general characterized by lower sensitivities than the technology parameters. However, the physico-chemical properties provided considerably higher contributions to the output uncertainty. Therefore, if we include waste composition data in the modeling, sensitivity analysis alone is not sufficient for identifying critical parameters in LCAs of waste management. If the uncertainty had been propagated only for the most sensitive parameters, only a fraction of the actual uncertainty information would have been included in the results.

The additivity of variances allows identification of specific parameters that are critical for the total uncertainty in each impact category and selection of a subset of parameters that can sufficiently well (or "sparsely") represent the uncertainty. The analytical approach can, together with the contribution analysis, be employed as an initial screening of parameters in order to prioritize data quality, or to focus on a limited number of parameters within the waste composition dataset. 
Monte Carlo simulations allow illustration of the skewness of output uncertainty distributions. This cannot be obtained with the analytical propagation. Through Monte Carlo simulations within EASETECH, the waste composition at every waste technology (or "unit processes") of the LCA model can also be retrieved as distributions. These distributions may provide indications of potential variability of the output flow compositions. Such variability may in turn affect the quality and recyclability of secondary materials. In some cases, these distributions in data were extremely skewed and had large uncertainties. This highlighted the importance of evaluating the shape of the distribution for parameters with large input uncertainties. For these parameters, the CVs calculated based on the analytical uncertainty were also high, suggesting that the analytically calculated CVs can act as indicators for situations when average impact values should be obtained from a Monte Carlo simulation.

\subsection{Waste composition uncertainty within comparative LCAs}

While the waste composition data evaluated in this study represent a wide uncertainty range found in the literature, the ranking of scenarios within the individual impact categories did not change when selecting specific datasets within this range (i.e. data represented by median values from either Götze et al., 2016 or Riber et al., 2009). This observation was due to the measured low sensitivity of the waste characterization data and to the higher contribution from technical parameters and external LCIs to the overall results. However, the absolute results changed. Again this illustrates the significance of the waste composition data and indicates that randomly selected waste datasets cannot be used for quantification of absolute environmental impacts associated with waste technologies. Case-specific waste composition data are needed for appropriate environmental assessment of waste solutions.

Including the variability of the waste composition data with input uncertainty distributions outbalanced the low sensitivity of the physico-chemical properties and dominated the results. For some impact categories, the CVs were exceptionally high. In these cases, the distributions of the results for different scenarios were overlapping and required a discernibility analysis for identification of the best 
performing scenario. As such, the GSA approach can be used to identify the specific parameters that determine, which of two scenarios provides the lowest impacts. For some impact categories, the technology choices and background process selections were critical. This is seen in the case where overlapping results were caused by the same physico-chemical properties, as in S1 and S2. However, for other impact categories, such as HTNC, the physico-chemical properties themselves determined the preference between S1 and S3.

\subsection{Uncertainty assessment and reference flow}

As indicated in Section 2.3, determination of both analytical and Monte Carlo based uncertainty may for some parameters challenge the assumption of a constant reference flow (please refer to the examples provided in Supplementary Material, Section S7). For the fractional and TS parameters, the variation between the analytical and sampled uncertainty was considerably higher than for the physicochemical and technology parameters. The analytical method allows the reference flow to be respected when calculating SCs. It provides another output uncertainty result than the Monte Carlo simulation, since the latter does not allow re-scaling to the reference flow when sampling from the fractional composition parameters. For comparison, in the example provided (Supplementary Material) the SCs of the fractional composition parameters were calculated also without respecting the reference flow. The results show considerably reduced differences between the analytical and sampled uncertainties. While this supports the observations previously mentioned, it is important to realize that the smaller differences between analytical and sampled uncertainties simply indicate a better fit with the Monte Carlo uncertainty propagation, rather than suggesting that the assumption of a constant reference flow can be ignored.

Only dedicated waste LCA models such as EASETECH allow propagation of uncertainties related to waste composition, but currently it is not possible to fully respect the reference flow. Therefore, both analytical and sampled uncertainty methods do only provide an approximation of the true uncertainty associated with the fractional and TS parameters. Waste composition data represent a 
hierarchy of relative information (Figure 2), and these data can be characterized as "closed data" (Aitchison, 1986; Chayes, 1971). In the future, descriptive statistics on data of a higher hierarchy than the physico-chemical should be analyzed within a compositional data analysis framework, as also highlighted by Edjabou et al. (2015b) and Pivnenko et al. (2016).

\section{Conclusions}

Although very few LCAs of waste management systems consider effects of the waste composition, this study showed that the choice of waste composition was critical for the results and their uncertainty for the systems assessed. On average, the waste composition contributed to $48 \%$ of the results and to $83 \%$ of the uncertainty of the results. The contribution to the results was direct (input-specific emissions), but also indirect (process-specific emissions and background processes affected by the waste characteristics), depending on the specific modelling of the waste management technologies. The large uncertainty of the waste physico-chemical data was particularly important for the uncertainty of the results, which were characterized by large and skewed distributions that sometimes included both impacts and savings. Waste-LCAs should thus include the effects of the waste composition and appropriately justify the choice of waste composition and its uncertainty. An understanding of the effects of the waste composition on the LCA model can be facilitated by appropriate utilization of uncertainty assessment tools. This study showed that sensitivity analysis alone is not sufficient due to the low sensitivity that characterizes the waste physico-chemical properties. On the other hand, contribution analysis can be utilized to identify direct and indirect contributions to the results. Systematic application of Global Sensitivity Analysis (GSA) can be used to identify which physico-chemical properties are critical for the results of the assessment, govern the output uncertainty and determine the priority between two scenarios.

\section{Acknowledgments}

Financial support is acknowledged from the Danish Research Council through the IRMAR project grant, as well as from the Technical University of Denmark. 


\section{Supplementary Material}

Detailed information on the LCA case study, waste composition and technology data and uncertainties as well as detailed results of sensitivity and uncertainty analyses are provided in the Supplementary Material freely available online.

\section{References}

Astrup, T., Riber, C., Pedersen, A.J., 2011. Incinerator performance: effects of changes in waste input and furnace operation on air emissions and residues. Waste Manag. Res. 29, 57-68.

Astrup, T.F., Tonini, D., Turconi, R., Boldrin, A., 2015. Life cycle assessment of thermal Waste-toEnergy technologies: Review and recommendations. Waste Manag. 37, 104-115.

Bisinella, V., Conradsen, K., Christensen, T.H., Astrup, T.F., 2016. A global approach for sparse representation of uncertainty in Life Cycle Assessments of waste management systems. Int. J. Life Cycle Assess. 21, 378-394.

Christensen, T.H., Simion, F., Tonini, D., Møller, J., 2009. Global warming factors modelled for 40 generic municipal waste management scenarios. Waste Manag. Res. 27, 871-84.

Clavreul, J., Baumeister, H., Christensen, T.H., Damgaard, A., 2014. An environmental assessment system for environmental technologies. Environ. Model. Softw. 60, 18-30.

Clavreul, J., Guyonnet, D., Christensen, T.H., 2012. Quantifying uncertainty in LCA-modelling of waste management systems. Waste Manag. 32, 2482-2495.

Edjabou, M.E., Jensen, M.B., Götze, R., Pivnenko, K., Petersen, C., Scheutz, C., Astrup, T.F., 2015. Municipal solid waste composition: sampling methodology, statistical analyses, and case study evaluation. Waste Manag. 36, 12-23. 
Edjabou, M.E., Pivnenko, K., Petersen, C., Scheutz, C., Astrup, T.F., 2015. Compositional data analysis of household food waste in Denmark, in: Abstract from 6th International Workshop on Compositional Data Analysis. Girona, Spain.

European Commission, 2010. Analysing of existing Environmental Impact Assessment methodologies for use in Life Cycle Assessment. International Reference Life Cycle Data System (ILCD) Handbook. European Commission, Joint Research Centre, Institute for Environment and Sustainability. Publications office of the European Union, Luxembourg.

European Commission, 2015. Closing the loop: Commission adopts ambitious new Circular Economy Package to boost competitiveness, create jobs and generate sustainable growth. Commission Press release, IP/15/6203.

Fruergaard, T., Astrup, T., 2011. Optimal utilization of waste-to-energy in an LCA perspective. Waste Manag. 31, 572-82.

Finnveden, G., Albertsson, A.-C., Berendson, J., Eriksson, E., Höglund, L.O., Karlsson, S., Sundqvist, J.-O., 1995. Solid waste treatment within the framework of life-cycle assessment. J. Clean. Prod. 3, 189-199.

Gentil, E.C., Damgaard, A., Hauschild, M., Finnveden, G., Eriksson, O., Thorneloe, S., Kaplan, P.O., Barlaz, M., Muller, O., Matsui, Y., Ii, R., Christensen, T.H., 2010. Models for waste life cycle assessment: review of technical assumptions. Waste Manag. 30, 2636-48.

Götze, R., Boldrin, A., Scheutz, C., Astrup, T.F., 2016. Physico-chemical characterisation of material fractions in household waste: overview of data in literature. Waste Manag. Res. 49, 3-14.

Jensen, M.B., Kromann, M., Lund Neidel, T., Bjørn Jakobsen, J., Møller, J., 2013. Miljø- og samfundsøkonomisk vurdering af muligheder for øget genanvendelse af papir, pap, plast, metal og organisk affald fra dagrenovation, Miljøprojekt nr. 1458. Miljøministeriet. Miljøstyrelsen. Copenhagen, Denmark. 
Jensen, M.B., Møller, J., Scheutz, C., 2016. Comparison of the organic waste management systems in the Danish-German border region using life cycle assessment (LCA). Waste Manag. 49, 491-504.

Köhler, A., Hellweg, S., Recan, E., Hungerbühler, K., 2007. Input-Dependent Life-Cycle Inventory Model of Industrial Wastewater-Treatment Processes in the Chemical Sector. Environ. Sci. Technol. 41, 5515-5522.

Laurent, A., Bakas, I., Clavreul, J., Bernstad, A., Niero, M., Gentil, E., Hauschild, M.Z., Christensen, T.H., 2014a. Review of LCA studies of solid waste management systems--part I: lessons learned and perspectives. Waste Manag. 34, 573-88.

Li, J., Lin, C., Huang, S., 2013. Considering Variations in Waste Composition during Waste InputOutput Modeling. J. Ind. Ecol. 17, 892-899.

Montejo, C., Tonini, D., Márquez, M. del C., Fruergaard Astrup, T., 2013. Mechanical-biological treatment: Performance and potentials. An LCA of 8 MBT plants including waste characterization. J. Environ. Manage. 128, 661-673.

Nielsen, P.H., Hauschild, M., 1998. Product specific emissions from municipal solid waste landfills. Int. J. Life Cycle Assess. 3, 158-168.

Passarini, F., Ciacci, L., Santini, A., Vassura, I., Morselli, L., 2012. Auto shredder residue LCA: implications of ASR composition evolution. J. Clean. Prod. 23, 28-36.

Pivnenko, K., Astrup, T.F., 2016. The challenge of chemicals in material lifecycles. Waste Manag. 56, $1-2$.

Pivnenko, K., Olsson, M., Götze, R., Eriksson, E., Astrup, T.F., 2016. Quantification of chemical contaminants in the paper and board fractions of municipal solid waste. Waste Manag. 51, 4354.

Riber, C., Petersen, C., Christensen, T.H., 2009. Chemical composition of material fractions in Danish household waste. Waste Manag. 29, 1251-1257. 
Slagstad, H., Brattebø, H., 2013. Influence of assumptions about household waste composition in waste management LCAs. Waste Manag. 33, 212-219.

Tonini, D., Astrup, T., 2012. Life-cycle assessment of a waste refinery process for enzymatic treatment of municipal solid waste. Waste Manag. 32, 165-76.

Turconi, R., Butera, S., Boldrin, A., Grosso, M., Rigamonti, L., Astrup, T., 2011. Life cycle assessment of waste incineration in Denmark and Italy using two LCA models. Waste Manag. Res. 29, 7890. 


\section{Table captions}

Table 1. Selected properties of the literature review-based waste composition utilized for the study provided in $\mathrm{kg}$. The fractional composition and the moisture content of Danish household waste were obtained from Edjabou et al. (2015) and Riber et al. (2009). "C bio": biogenic C, "C bio and": anaerobically degradable C. The full dataset can be found in Table S8 in the Supplementary Material.

Table 2. Quantitative absolute contribution to the results for each scenario and impact category subdivided into: input-specific and process-specific/external LCI per property of reference flow or per unit reference flow.

Table 3. Results of the discernibility analysis. The percentages represent the probability of S1 to perform better than the scenarios in the rows, for each impact category.

\section{Figure captions}

Figure 1. Waste-specific LCA general structure and terminology used throughout the assessment. Waste composition data can have a direct (input-specific) and indirect (external LCIs, process-specific per property of reference flow) effect on results.

Figure 2. Normalized results and contribution analysis results for S1, S2 and S3. The black diamonds indicate net results obtained with median values from Götze et al. (2016). The white diamonds indicate net results obtained with the dataset of Riber et al. (2009). Black and white diamonds correspond to net

results in Figure 4. The contribution analysis focuses on direct and indirect influence of waste composition on the results of S1, S2 and S3. 
Figure 3. Percent contribution of physico-chemical and technology parameters to the total analytical output uncertainty. The technology parameters were subdivided into "technology" and "technology per property of input".

Figure 4. LCIA results obtained by means of Monte Carlo simulations. The columns represent the averages from the Monte Carlo sampling. The error bars represent the $5^{\text {th }}$ and the $95^{\text {th }}$ percentiles of the distributions. Black and white diamonds show where the median results from Götze et al. (2016) and the Riber et al. (2009) locate within the distributions, and correspond to net results in Figure 2. 
Table 1. Selected properties of the literature review-based waste composition utilized for the study provided in $\mathrm{kg}$. The fractional composition and the moisture content of Danish household waste were obtained from Edjabou et al. (2015) and Riber et al. (2009). "C bio": biogenic C, "C bio and": anaerobically degradable C.

The full dataset can be found at Table S8 in the Supplementary Material.

\begin{tabular}{|c|c|c|c|c|c|c|c|c|c|c|c|c|c|c|c|c|c|c|}
\hline \multirow[b]{2}{*}{ Waste material fraction name } & \multicolumn{2}{|c|}{$\begin{array}{c}\text { Edjabou et al. (2015) } \\
\text { Total Wet Weight }\end{array}$} & \multicolumn{2}{|c|}{ Riber et al. (2009) } & \multicolumn{14}{|c|}{ Götze et al. (2016) } \\
\hline & $\begin{array}{l}\text { Total We } \\
(\mathrm{kg})\end{array}$ & $\begin{array}{l}\text { Weight } \\
(\%)\end{array}$ & $\begin{array}{l}\text { Water } \\
(\mathrm{kg})\end{array}$ & $\begin{array}{l}\text { TS } \\
(\mathrm{kg})\end{array}$ & $\begin{array}{l}\text { VS } \\
(\mathrm{kg})\end{array}$ & $\begin{array}{l}\text { Energy } \\
(\mathrm{kg})\end{array}$ & $\begin{array}{l}\text { C bio } \\
(\mathrm{kg})\end{array}$ & $\begin{array}{l}\text { C bio and } \\
(\mathrm{kg})\end{array}$ & $\begin{array}{l}\text { C fossil } \\
(\mathrm{kg})\end{array}$ & $\begin{array}{l}\mathbf{N} \\
(\mathrm{kg})\end{array}$ & $\begin{array}{l}\mathbf{P} \\
(\mathrm{kg})\end{array}$ & $\begin{array}{l}\text { As } \\
(\mathrm{kg})\end{array}$ & $\begin{array}{l}\text { Cd } \\
(\mathrm{kg})\end{array}$ & $\begin{array}{l}\mathrm{Cr} \\
(\mathrm{kg})\end{array}$ & $\begin{array}{l}\mathrm{Cu} \\
(\mathrm{kg})\end{array}$ & $\begin{array}{l}\mathbf{H g} \\
(\mathrm{kg})\end{array}$ & $\begin{array}{l}\mathbf{P b} \\
(\mathrm{kg})\end{array}$ & $\begin{array}{l}\mathrm{Zn} \\
(\mathrm{kg})\end{array}$ \\
\hline Food waste & 449 & $45 \%$ & 326.9 & 122.1 & 96.7 & 1687.6 & 58.0 & 31.1 & 0.6 & 3.7 & 0.6 & $8.2 \mathrm{E}-04$ & $4.9 \mathrm{E}-05$ & $6.4 \mathrm{E}-04$ & $1.1 \mathrm{E}-03$ & $1.7 \mathrm{E}-05$ & $1.3 \mathrm{E}-03$ & $6.8 \mathrm{E}-03$ \\
\hline Gardening waste & 54 & $5 \%$ & 26.9 & 27.1 & 23.3 & 347.5 & 11.1 & 2.0 & 0.2 & 0.3 & 0.0 & $6.5 \mathrm{E}-05$ & $6.8 \mathrm{E}-06$ & $4.4 \mathrm{E}-04$ & $3.5 \mathrm{E}-04$ & $1.1 \mathrm{E}-06$ & $2.6 \mathrm{E}-04$ & $1.7 \mathrm{E}-03$ \\
\hline Paper and cardboard & 98 & $10 \%$ & 11.3 & 86.7 & 75.4 & 1162.1 & 34.9 & 14.5 & 0.2 & 0.2 & 0.0 & $9.5 \mathrm{E}-05$ & $2.6 \mathrm{E}-05$ & $1.7 \mathrm{E}-03$ & $3.0 \mathrm{E}-03$ & $8.5 \mathrm{E}-06$ & $1.5 \mathrm{E}-03$ & $6.7 \mathrm{E}-03$ \\
\hline Composites & 54 & $5 \%$ & 2.6 & 51.4 & 43.2 & 924.8 & 18.0 & 4.7 & 5.1 & 0.2 & 0.0 & $1.0 \mathrm{E}-05$ & $1.3 \mathrm{E}-04$ & $9.5 \mathrm{E}-04$ & $3.1 \mathrm{E}-03$ & $1.3 \mathrm{E}-06$ & $1.7 \mathrm{E}-03$ & $9.0 \mathrm{E}-03$ \\
\hline Plastic & 148 & $15 \%$ & 12.7 & 135.3 & 131.2 & 4119.3 & 0.5 & 0.0 & 98.2 & 0.3 & 0.0 & $3.0 \mathrm{E}-04$ & $5.1 \mathrm{E}-04$ & $1.0 \mathrm{E}-02$ & 7.3E-03 & $1.8 \mathrm{E}-05$ & $1.3 \mathrm{E}-02$ & $3.5 \mathrm{E}-02$ \\
\hline Combustibles & 143 & $14 \%$ & 41.3 & 101.7 & 92.9 & 1973.3 & 31.0 & 1.1 & 20.3 & 1.2 & 0.0 & $5.1 \mathrm{E}-04$ & $1.0 \mathrm{E}-04$ & $5.7 \mathrm{E}-03$ & $3.4 \mathrm{E}-03$ & $1.1 \mathrm{E}-05$ & $5.5 \mathrm{E}-03$ & $2.3 \mathrm{E}-02$ \\
\hline Metal & 19 & $2 \%$ & 1.3 & 17.7 & 0.6 & 0.0 & 0.1 & 0.0 & 0.0 & 0.0 & 0.0 & $1.1 \mathrm{E}-04$ & 3.7E-05 & 2.7E-03 & $1.7 \mathrm{E}-03$ & $4.4 \mathrm{E}-07$ & $5.8 \mathrm{E}-04$ & $1.8 \mathrm{E}-03$ \\
\hline Glass & 21 & $2 \%$ & 0.5 & 20.5 & 0.2 & 0.0 & 0.1 & 0.0 & 0.0 & 0.0 & 0.0 & 7.3E-04 & $2.3 \mathrm{E}-05$ & $2.0 \mathrm{E}-03$ & $1.7 \mathrm{E}-04$ & $8.2 \mathrm{E}-07$ & $1.7 \mathrm{E}-03$ & $1.1 \mathrm{E}-03$ \\
\hline Inert & 14 & $1 \%$ & 1.7 & 12.3 & 0.4 & 0.3 & 0.2 & 0.0 & 0.0 & 0.0 & 0.0 & $1.3 \mathrm{E}-04$ & $1.8 \mathrm{E}-05$ & $9.2 \mathrm{E}-04$ & $4.4 \mathrm{E}-04$ & $1.2 \mathrm{E}-06$ & $1.1 \mathrm{E}-03$ & 4.2E- 03 \\
\hline Total & 1000 & & 425.2 & 574.8 & 463.8 & 10214.7 & 153.9 & 53.5 & 124.7 & 5.9 & 0.8 & $2.8 \mathrm{E}-03$ & $9.0 \mathrm{E}-04$ & $2.5 \mathrm{E}-02$ & $2.1 \mathrm{E}-02$ & $5.9 \mathrm{E}-05$ & $2.7 \mathrm{E}-02$ & $9.0 \mathrm{E}-02$ \\
\hline
\end{tabular}


Table 2. Quantitative absolute contribution to the results for each scenario and impact category subdivided into: input-specific and process-specific/external LCI per property of reference flow or per unit reference flow.

\begin{tabular}{|c|c|c|c|c|c|c|c|c|c|c|c|c|c|c|}
\hline & GW & OD & HTC & HTNC & IR & POF & $\mathrm{FE}$ & $\mathrm{ME}$ & $\mathrm{ET}$ & RDFOS & $\mathrm{RD}$ & TA & $\mathrm{TE}$ & $\mathrm{PM}$ \\
\hline \multicolumn{15}{|l|}{ Scenario 1} \\
\hline Input-specific & $30 \%$ & $0 \%$ & $2 \%$ & $3 \%$ & $0 \%$ & $0 \%$ & $0 \%$ & $0 \%$ & $0 \%$ & $0 \%$ & $0 \%$ & $0 \%$ & $0 \%$ & $0 \%$ \\
\hline External LCI per property reference flow & $49 \%$ & $2 \%$ & $23 \%$ & $37 \%$ & $2 \%$ & $51 \%$ & $0 \%$ & $50 \%$ & $3 \%$ & $51 \%$ & $0 \%$ & $51 \%$ & $50 \%$ & $50 \%$ \\
\hline Process-specific per property reference flow & $0 \%$ & $0 \%$ & $0 \%$ & $0 \%$ & $0 \%$ & $0 \%$ & $0 \%$ & $0 \%$ & $0 \%$ & $0 \%$ & $0 \%$ & $0 \%$ & $0 \%$ & $0 \%$ \\
\hline External LCI and process-specific per unit reference flow & $21 \%$ & $98 \%$ & $76 \%$ & $60 \%$ & $98 \%$ & $49 \%$ & $100 \%$ & $50 \%$ & $97 \%$ & $49 \%$ & $100 \%$ & $49 \%$ & $50 \%$ & $50 \%$ \\
\hline \multicolumn{15}{|l|}{ Scenario 2} \\
\hline Input-specific & $28 \%$ & $0 \%$ & $68 \%$ & $91 \%$ & $0 \%$ & $0 \%$ & $0 \%$ & $24 \%$ & $77 \%$ & $0 \%$ & $0 \%$ & $1 \%$ & $1 \%$ & $0 \%$ \\
\hline External LCI per property reference flow & $46 \%$ & $3 \%$ & $7 \%$ & $1 \%$ & $3 \%$ & $47 \%$ & $90 \%$ & $35 \%$ & $1 \%$ & $34 \%$ & $0 \%$ & $48 \%$ & $47 \%$ & $49 \%$ \\
\hline Process-specific per property reference flow & $0 \%$ & $0 \%$ & $6 \%$ & $6 \%$ & $0 \%$ & $0 \%$ & $0 \%$ & $0 \%$ & $6 \%$ & $0 \%$ & $0 \%$ & $0 \%$ & $0 \%$ & $0 \%$ \\
\hline External LCI and process-specific per unit reference flow & $25 \%$ & $97 \%$ & $19 \%$ & $2 \%$ & $97 \%$ & $53 \%$ & $10 \%$ & $40 \%$ & $16 \%$ & $66 \%$ & $100 \%$ & $51 \%$ & $52 \%$ & $51 \%$ \\
\hline \multicolumn{15}{|l|}{ Scenario 3} \\
\hline Input-specific & $32 \%$ & $0 \%$ & $0 \%$ & $0 \%$ & $0 \%$ & $0 \%$ & $0 \%$ & $0 \%$ & $0 \%$ & $0 \%$ & $0 \%$ & $0 \%$ & $0 \%$ & $0 \%$ \\
\hline External LCI per property reference flow & $10 \%$ & $0 \%$ & $1 \%$ & $14 \%$ & $15 \%$ & $19 \%$ & $0 \%$ & $1 \%$ & $0 \%$ & $17 \%$ & $0 \%$ & $26 \%$ & $24 \%$ & $28 \%$ \\
\hline Process-specific per property reference flow & $38 \%$ & $99 \%$ & $97 \%$ & $37 \%$ & $0 \%$ & $53 \%$ & $80 \%$ & $96 \%$ & $75 \%$ & $0 \%$ & $0 \%$ & $23 \%$ & $42 \%$ & $11 \%$ \\
\hline External LCI and process-specific per unit reference flow & $21 \%$ & $1 \%$ & $2 \%$ & $48 \%$ & $85 \%$ & $28 \%$ & $20 \%$ & $2 \%$ & $25 \%$ & $83 \%$ & $100 \%$ & $51 \%$ & $34 \%$ & $61 \%$ \\
\hline
\end{tabular}


Table 3. Results of the discernibility analysis. The percentages represent the probability of S1 to perform better than the scenarios in the rows, for each impact category.

\begin{tabular}{|c|c|c|c|c|c|c|c|c|c|c|c|c|c|c|}
\hline \multirow{2}{*}{ S1 compared to: } & \multicolumn{14}{|c|}{ Impact category } \\
\hline & GW & OD & HTC & HTNC & IR & POF & $\mathrm{FE}$ & $\mathrm{ME}$ & ET & RDFOS & $\mathrm{RD}$ & TA & $\mathrm{TE}$ & PM \\
\hline S2 & $68 \%$ & $59 \%$ & $100 \%$ & $100 \%$ & $59 \%$ & $76 \%$ & $0 \%$ & $98 \%$ & $100 \%$ & $100 \%$ & $97 \%$ & $73 \%$ & $82 \%$ & $69 \%$ \\
\hline S3 & $97 \%$ & $100 \%$ & $100 \%$ & $57 \%$ & $100 \%$ & $100 \%$ & $100 \%$ & $100 \%$ & $100 \%$ & $100 \%$ & $81 \%$ & $100 \%$ & $100 \%$ & $100 \%$ \\
\hline
\end{tabular}




\section{ACCEPTED MANUSCRIPT}

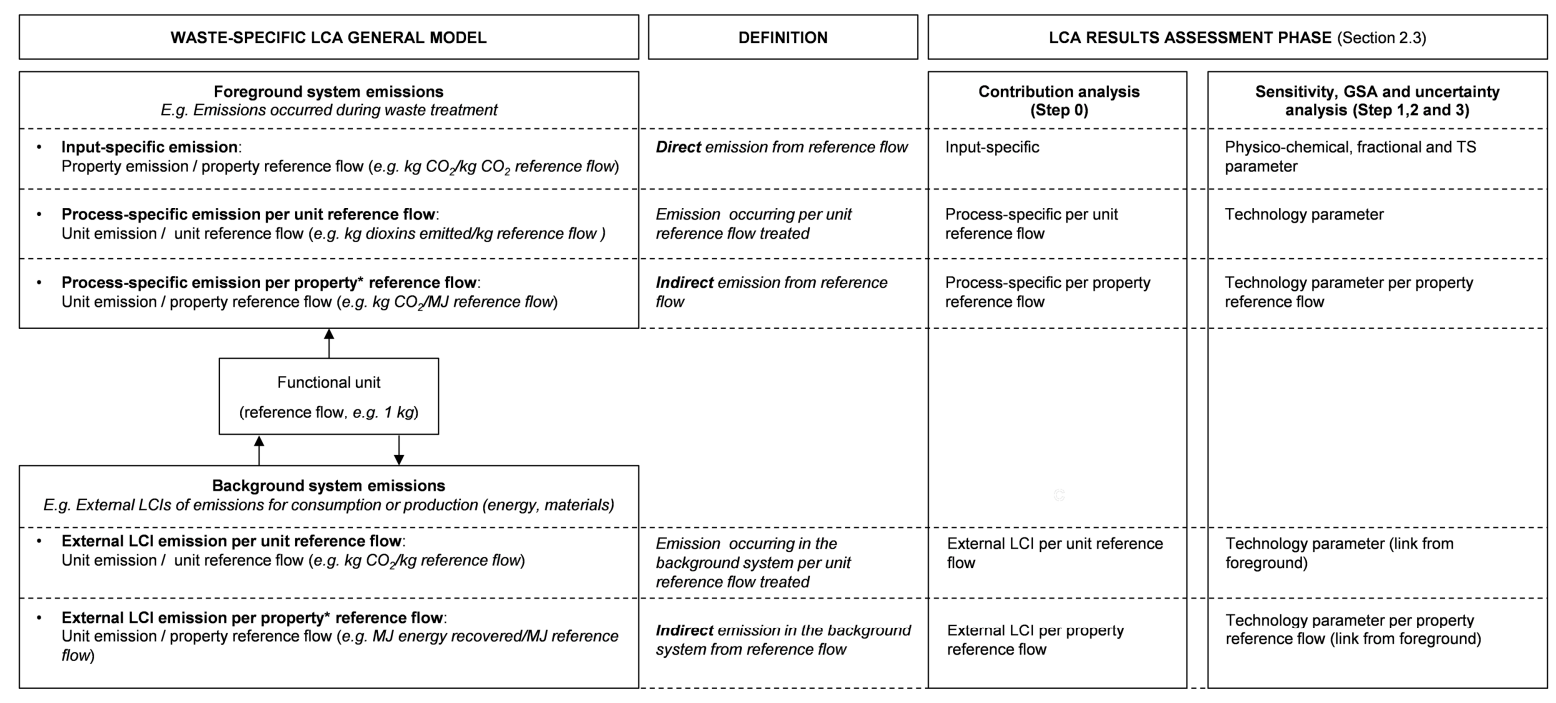

* Property of reference flow: Physico-chemical waste characteristics, total solids (TS) content 

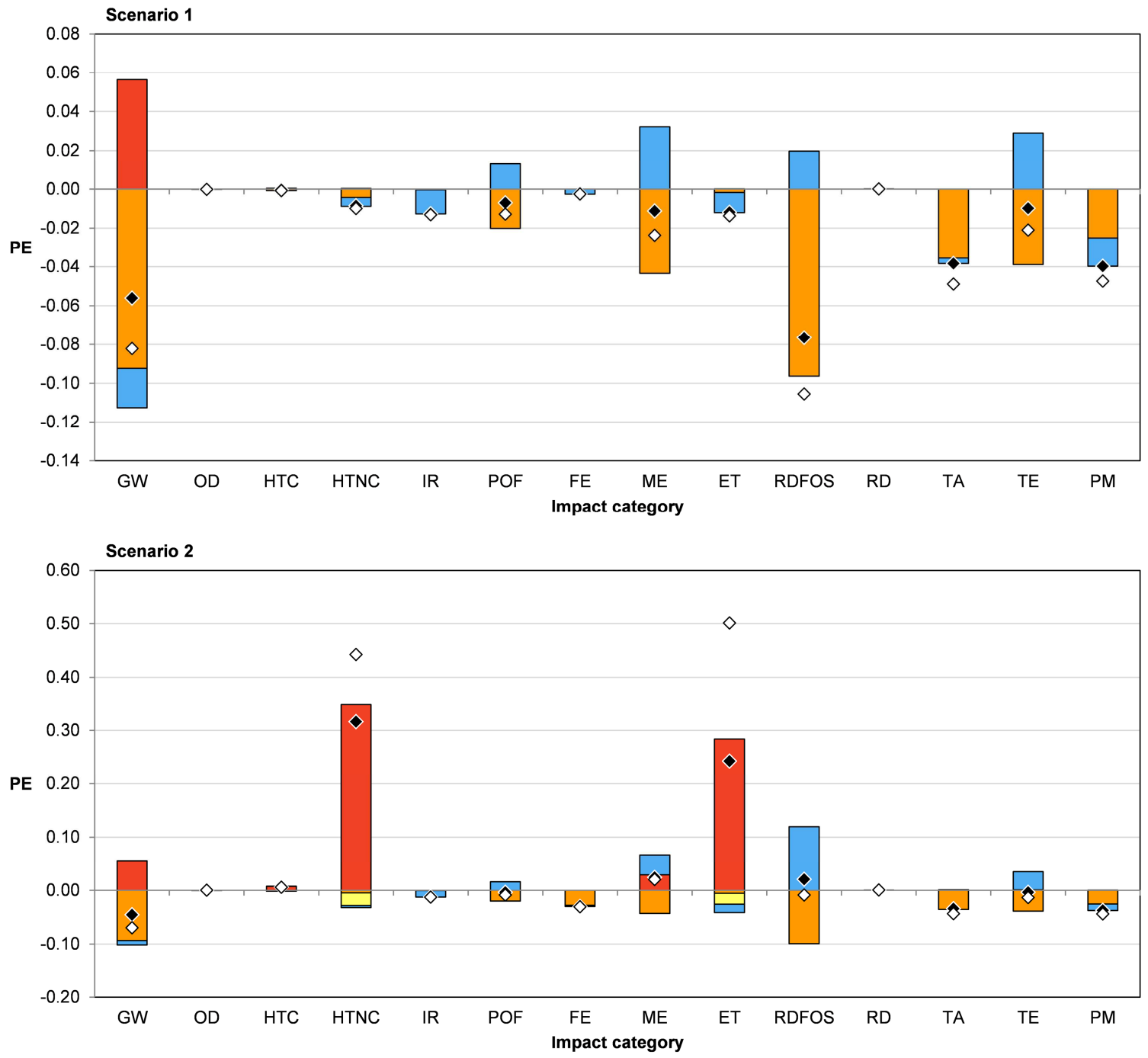

Scenario 3

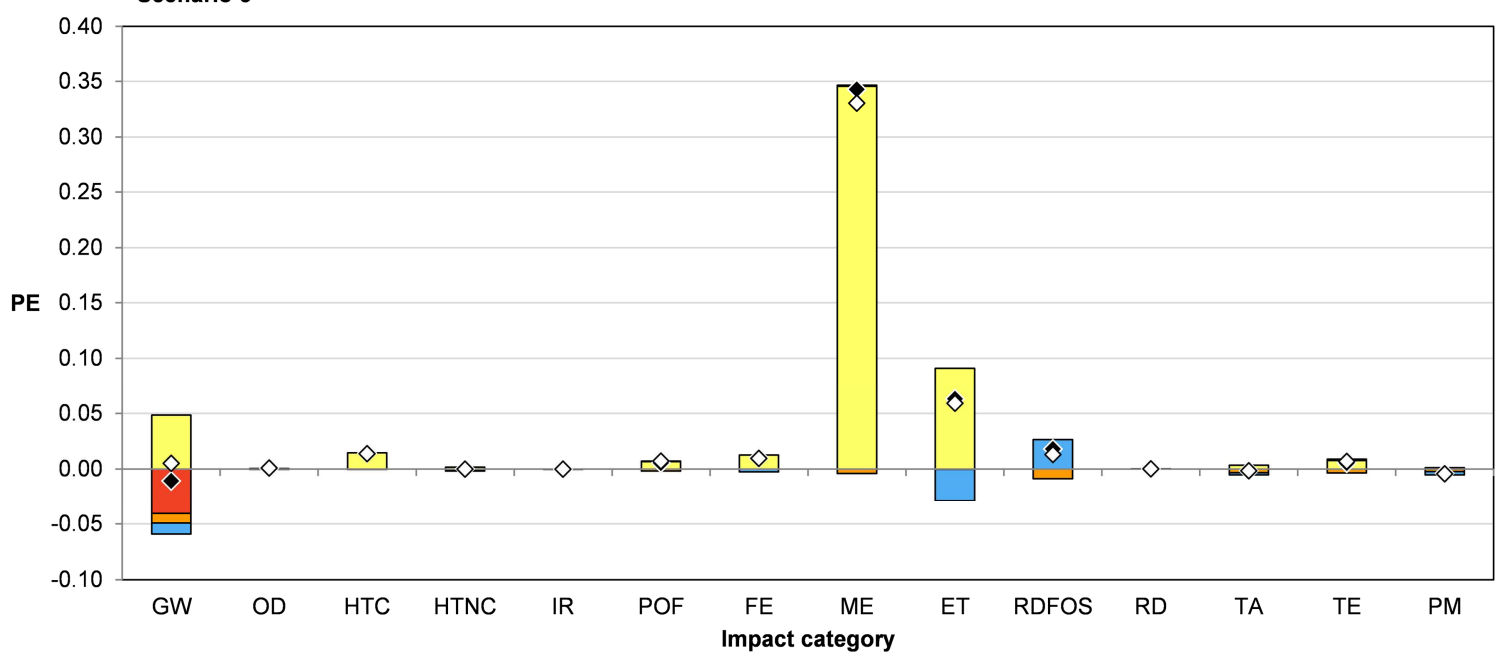

口Input-specific

$\square$ Process-specific per property reference flow - Net, Götze et al. (2016) $\square$ External LCl per property reference flow

$\square$ External $\mathrm{LCl}$ and process-specific per unit reference flow $\diamond$ Net, Riber et al. (2009) 

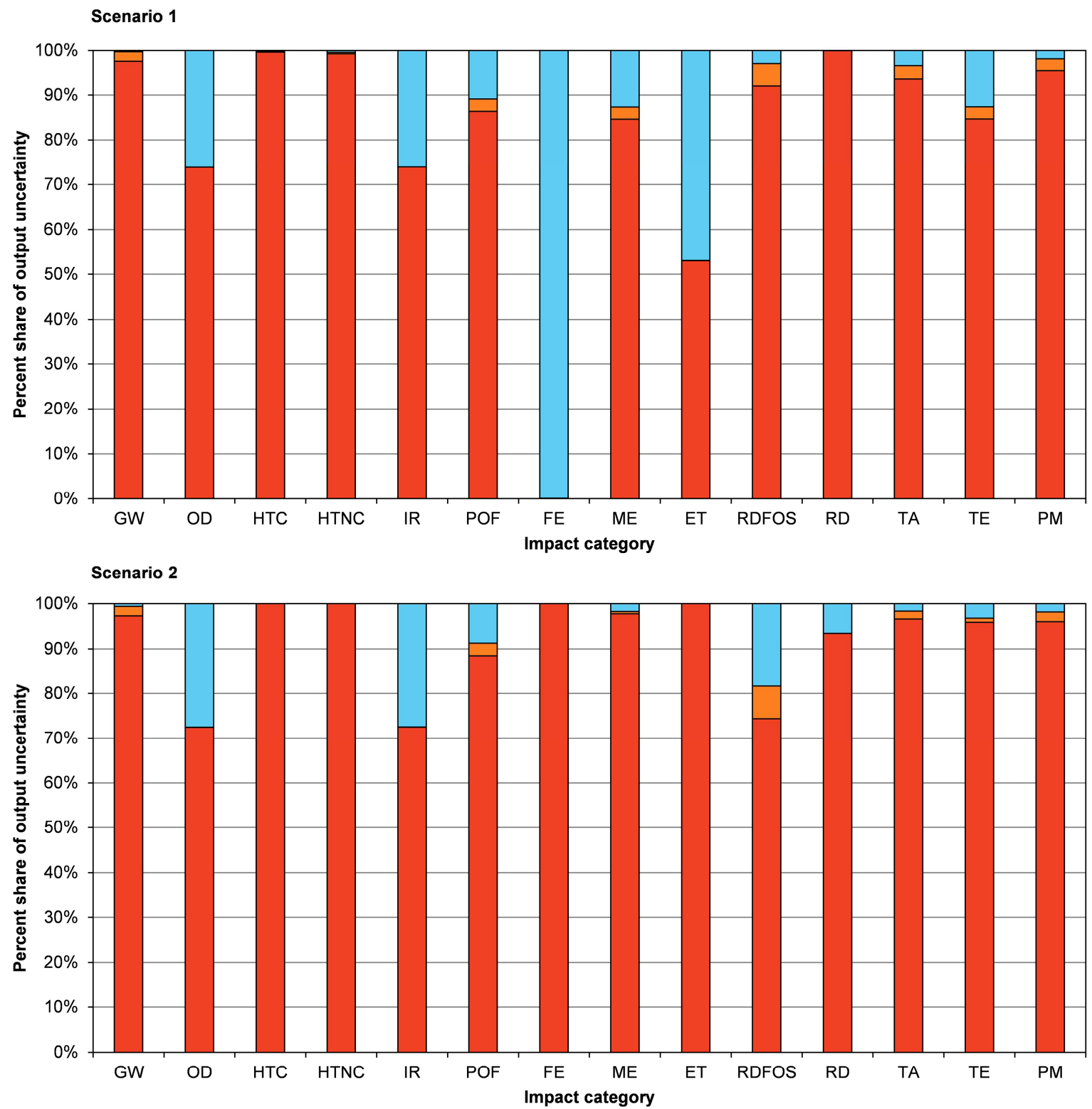

Scenario 3

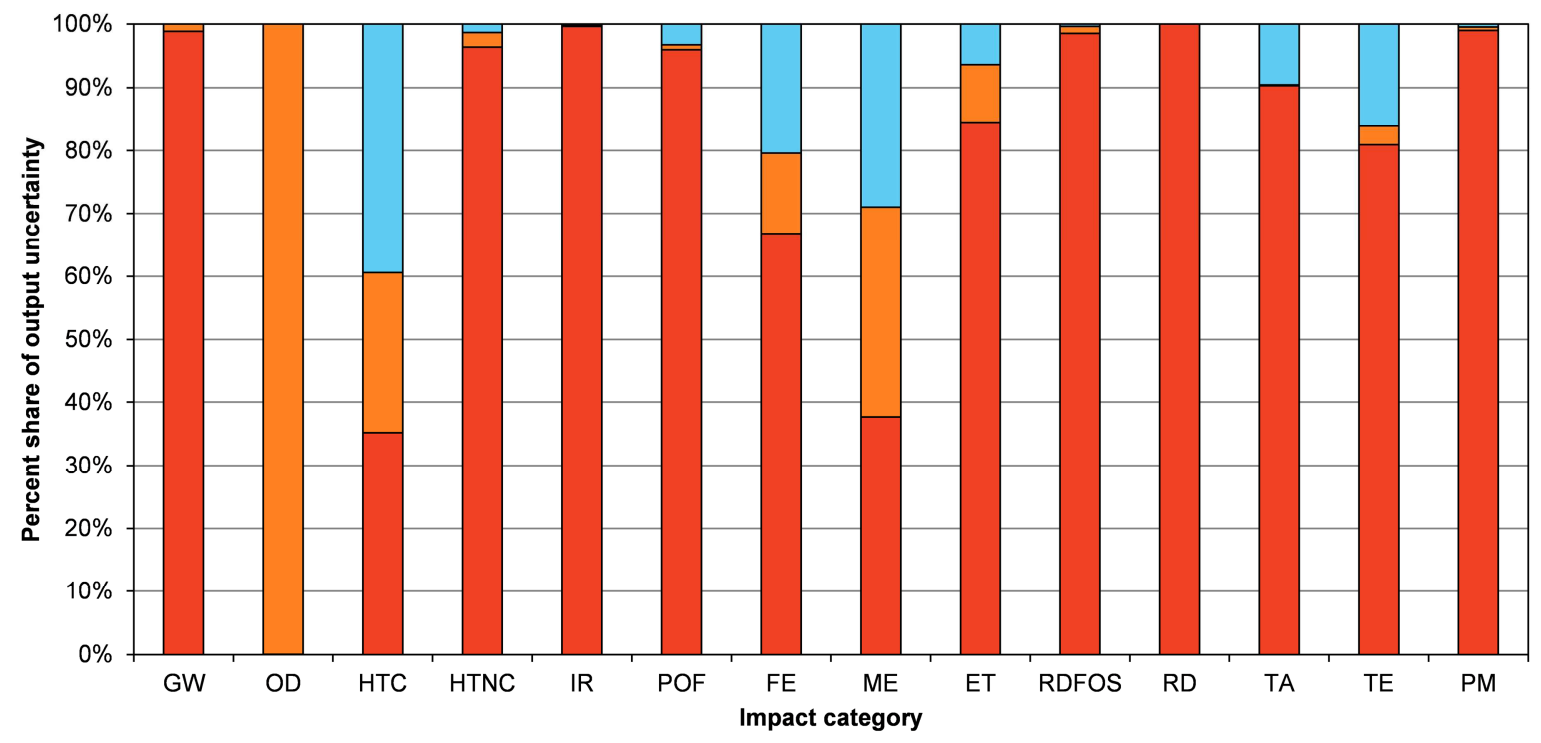

口Physico-chemical $\quad$ Technology connected to the input $\quad$ Technology 

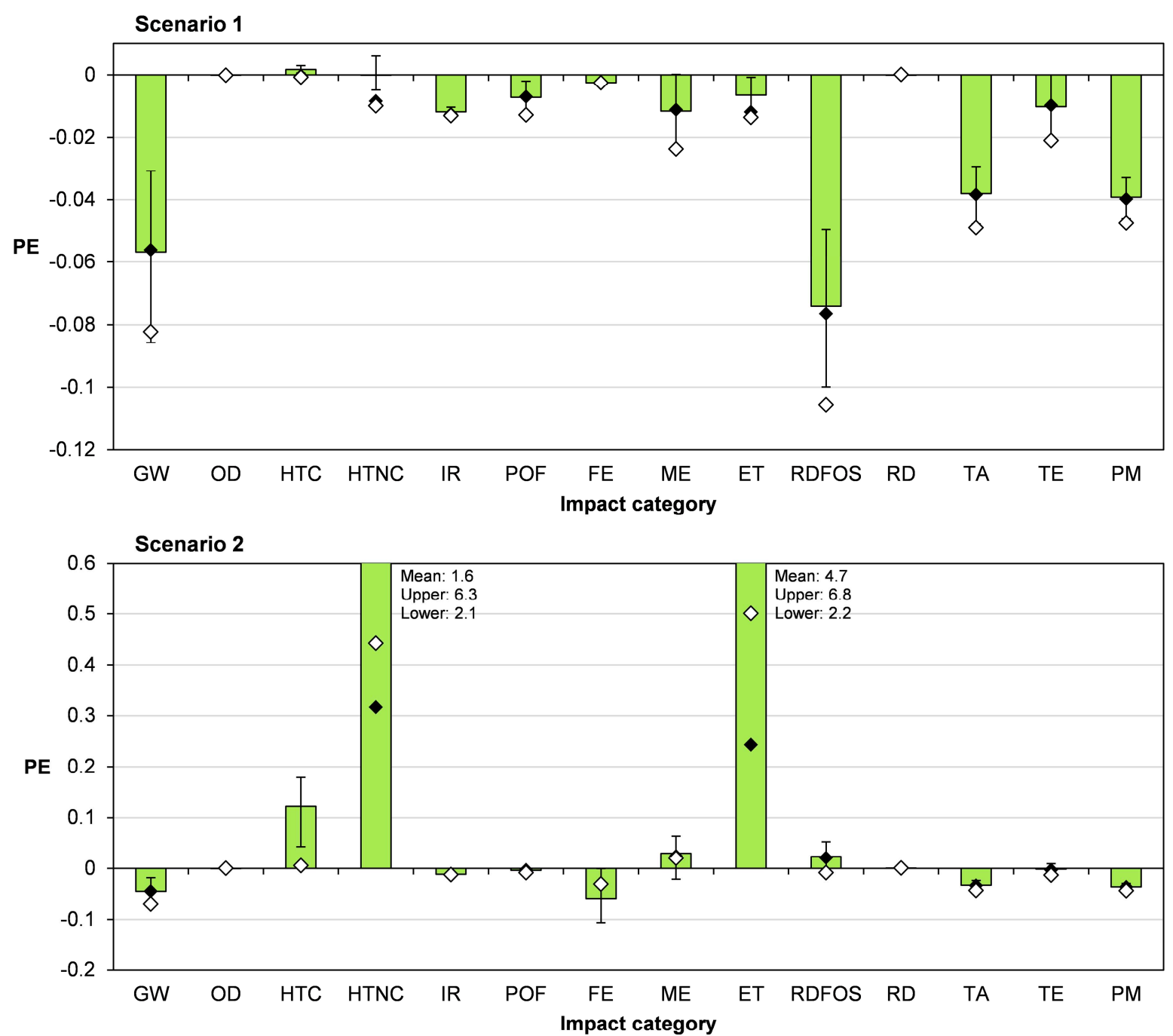

Scenario 3

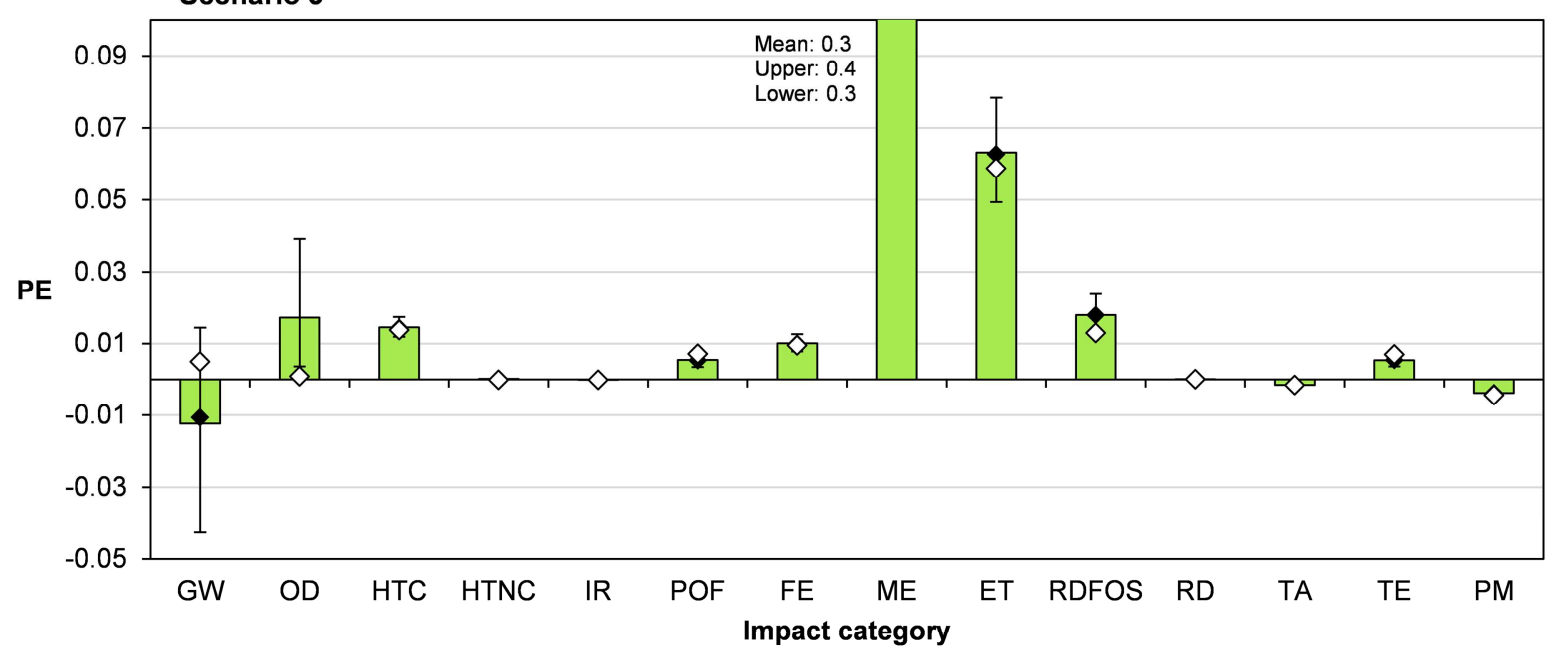

口Götze et al. (2016), Monte Carlo average $\diamond$ Götze et al. (2016), median $\diamond$ Riber et al. (2009) 
Highlights

- Effects of waste composition on results and uncertainty of waste LCA models

- Global Sensitivity Analysis applied to waste composition data within waste LCA models

- Uncertainty can be sparsely represented by few physico-chemical properties 